\title{
Vibration Analysis of an Axially Moving Plate Based on Sound Time-Frequency Analysis
}

\author{
Qianqian Lu \\ Mechanical Engineering Department, Zhejiang University City College, Hangzhou, Zhejiang 310015, P.R. China. \\ Key Laboratory of Special Purpose Equipment and Advanced Manufacturing Technology, Ministry of Education, \\ Zhejiang University of Technology, Hangzhou 310014, P.R. China.
}

\author{
Wei Shao, Yangfang Wu and Chunlin Xia \\ Mechanical Engineering Department, Zhejiang University City College, Hangzhou, Zhejiang 310015, P.R. China.
}

(Received 12 September 2017; accepted 11 December 2017)

In some types of non-contact measuring systems, vibrating motion has negative effects on accuracy. Therefore, there is a need to analyze and monitor the motion state of a moving part using a low-cost scheme. This study focused on the vibration analysis and monitoring of a poly-crystalline silicon solar wafer carried by a pair of parallel moving strings, separated by a distance. Based on the sound data series picked up by a low-cost microphone and using a time-frequency analysis method, namely, the Hilbert-Huang transform (HHT) method, the low frequency features of the moving wafer could be determined quantitatively. The results showed that the motion of the moving wafer was sensitive to speed and string tension. By comparison, the average marginal spectrum should be treated as the basis for quantitative vibration monitoring, especially for a system with a strict requirement in terms of motion smoothness.

\section{INTRODUCTION}

The dynamics of axially moving systems has been studied over many years. Recently, a review paper on the characteristics of axially moving continua has been published. ${ }^{1}$ Because of the complexity of the mathematical model of an axially moving plate, many types of numerical methods, such as the mixed Finite Element Method (FEM), modal spectral element method, and finite strip method have been used. ${ }^{2-8}$ In addition, Ghayesh and Amabili reported the geometrical nonlinear dynamics of an axially moving plate based on the direct time integration method. ${ }^{9}$ Using the pseudo-arclength continuation technique, Ghayesh et al. investigated the nonlinear dynamics of the forced motion of an axially moving plate and the effect of system parameters, such as the axial speed and pretension on resonant responses. ${ }^{10}$ The finite difference method, perturbation techniques, direct time integration, and pseudoarclength continuation technique are also used to explore the nonlinear dynamic behaviors of moving continua. ${ }^{11-19}$ Considering viscoelastic characteristics, some researchers have taken an interest in viscoelastic moving panels, strings, plates, and webs. $^{20-24}$

The characteristics of axially moving continua under special constraints have been reported. Based on the Von Kármán large deflection equations of thin plates, considering the influences of the axial movement of the plate, axial tension, fluid-structure interaction, and foundation displacement, and by adopting a numerical method and the approximate analysis method, Li studied the characteristics of 1:3 internal resonances and their bifurcations for an axially moving unidirec- tional plate, partially immersed in a fluid under foundation displacement excitation. ${ }^{25}$ Tang presented a vibration characteristic analysis and numerical confirmation of an axially moving plate with viscous damping. ${ }^{26}$ The complex frequencies, complex modes, and critical speeds of an axially moving plate, with viscous damping, were investigated using the complex mode approach. The effects of some parameters, such as viscous damping coefficients, axial speeds, aspect ratios, stiffness ratios, and support stiffness parameters, on complex frequencies and critical speeds were also examined. The natural frequencies, complex modes, and critical speeds of an axially moving rectangular plate, which is partially immersed in a fluid and subjected to a pre-tension, were investigated by using the classical thin plate theory. ${ }^{27}$ The nonlinear vibrations of an axially accelerating multi-supported string were discussed by using the Hamilton principle and multiple timescale methods. ${ }^{28}$

Experimental studies of an axially moving system have also attracted attention..$^{29-35}$ The authors presented experimental results on the vibration characteristics of axially moving strings. ${ }^{32,33}$ The vibrating characteristics of a moving plate were demonstrated by using the Hilbert-Huang transform (HHT) method. ${ }^{34}$ To quantitatively express the motion (including pitch and roll) of a moving plate, three capacitive sensors were used and a motion indicator was introduced.

In engineering applications, such as some types of noncontact measuring systems, vibrating motion has negative effects on accuracy; therefore, there is a need to monitor the motion state of the moving part by using a low-cost scheme. In the present study, through sound signal analysis, we focus on 


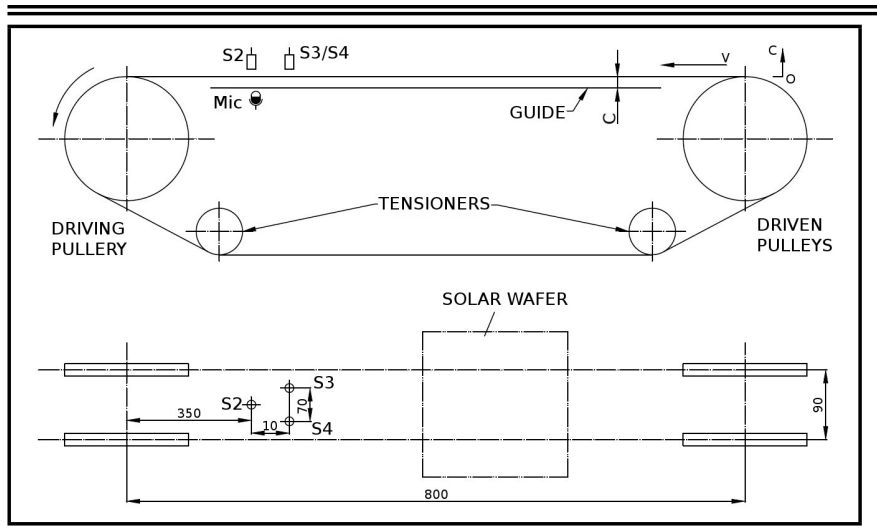

Figure 1. The schematic of test stand.

the vibration analysis and monitoring of a poly-crystalline silicon solar wafer, carried by a pair of parallel moving strings separated by a distance. The experimental system is similar to that presented by $\mathrm{Wu}$ et al. ${ }^{34}$ Based on a sound data series, the time-frequency features of the moving wafer were analyzed using HHT, which is considered a powerful time-frequency analysis method. ${ }^{35-39}$ In Section 2, the experimental system and its parameters are briefly introduced. As an example, a data series was investigated using HHT to examine the features of vibration. The Hilbert spectra and marginal spectra of the moving part (solar wafer in this case) are detailed; the effects of the system parameters on motion are presented in Section 3; finally, the conclusions are presented in Section 4.

\section{EXPERIMENTAL SYSTEM}

A system schematic is shown in Fig. 1, which includes two seamless parallel polyester strings, with a diameter of $6 \mathrm{~mm}$ and separated by $90 \mathrm{~mm}$. The parameters of the test system and the sample solar wafers are listed in Table $1 .{ }^{34}$ To drive the system, a step motor is used with different velocities. Two polytetrafluoroethylene guides, that almost cover the span, are arranged to reduce string vibrations to an acceptable level. The clearance $C$ (between the string and the guide), and the initial tension $P$ in the strings, can be adjusted separately. A capacitive-type microphone (D-78), with a frequency response range of $70 \mathrm{~Hz}-20 \mathrm{kHz}$, and sensitivity of $-37 \mathrm{~dB} \pm 3 \mathrm{~dB}$, was used to pick up the sound when the wafer passed by; a $16 \mathrm{kHz}$ sampling rate was used. Capacitance sensors S2, S3, and S4 were used to monitor the transverse vibrations; however, the details are not covered in this paper. In this experiment, clearance $C$ remains at $1.4 \mathrm{~mm}$ and uniform axial velocities of $152.5,305,457.5,610,762.5$, and $915 \mathrm{~mm} / \mathrm{s}$ are used. Two initial tensions in the strings, of 20.5 and $30 \mathrm{~N}$, which corresponded to different velocities, were set by the tensioners.

\section{TIME-FREQUENCY ANALYSIS}

In this section, first, a short introduction of the HHT method is presented. As an example, based on a sound series, the features were extracted through the Ensemble Empirical Mode Decomposition (EEMD), Hilbert Spectrum (HSP) and
Table 1. Parameters for test system and sample solar wafers.

\begin{tabular}{||c|c|}
\hline Variable & Value \\
\hline Diameter of driving/driven pulley & $86 \mathrm{~mm}$ \\
\hline Length of guide & $610 \mathrm{~mm}$ \\
\hline String mass per unit length & $0.0399 \mathrm{~kg} / \mathrm{m}$ \\
\hline Eccentricities of driving pulleys* & $25,36 \mu \mathrm{m}$ \\
\hline Eccentricities of driven pulleys & $8,25 \mu \mathrm{m}$ \\
\hline Solar wafer size & $156 \times 156 \mathrm{~mm}$ \\
\hline Weight of wafer \#1 & $11.09 \mathrm{~g}$ \\
\hline Weight of wafer \#2 & $11.08 \mathrm{~g}$ \\
\hline Weight of wafer \#3 & $11.44 \mathrm{~g}$ \\
\hline
\end{tabular}

* The driving and driven pulleys were paired up as follows: a driving pulley with an eccentricity of $25 \mu \mathrm{m}$ matches a driven pulley with an eccentricity of $8 \mu \mathrm{m}$; in the other pair, $36 \mu \mathrm{m}$ corresponds to $25 \mu \mathrm{m}$.

Marginal Spectrum (MSP). Even though it requires more computation time, EEMD, in which finite-amplitude white noises are added to the series to be processed and ensemble means as decomposition results, was chosen for this analysis to avoid possible inter-wave modulations and to suppress possible intermittence. ${ }^{32,33,36}$

\subsection{HHT}

The HHT method consists of Empirical Mode Decomposition (EMD), EEMD, and Hilbert spectral analysis. ${ }^{35,36}$

\subsubsection{EMD}

Given a time series $x(t)$, through a sifting process, one can write

$$
x(t)=\sum_{k}^{n} C_{k}(t)+r_{n} ;
$$

where $r_{n}$ is the residue of $x(t)$, and $C_{k}$ represents the intrinsic mode functions (IMFs), which are simple oscillatory functions with varying amplitude and frequency that satisfy the following two requirements: (1) over the entire dataset, the number of extrema and zero crossings must either be equal or differ mostly by one; (2) at any data point, the mean value of the envelope defined by local maxima and the envelope defined by local minima is zero. ${ }^{35}$ The envelopes are generally produced using a natural cubic spline, to fit the local maxima or local minima, respectively. The IMFs carry the characteristic time scales, which are directly derived from, and based on, the data, without any assumptions. If the residue is excluded, $x(t)$ can be expressed as follows:

$$
x(t)=\sum_{k=1}^{n} \alpha_{k}(t) \cos \theta_{k}(t)=\sum_{k=1}^{n} \alpha_{k}(t) \cos \left[\int_{0}^{t} \omega_{k}(\tau)\right] d \tau ;
$$

where $\alpha_{k}(t)$ is the amplitude of the IMF, $\theta_{k}(t)$ is the phase, and $\omega_{k}$ is the instantaneous frequency. After using EMD to obtain the IMFs, the instantaneous frequency (IF) of each IMF can be calculated using many possible methods such as Direct Quadrature, Normalized Hilbert Transform, or the generalized Zero-crossing Method. If necessary, the orthogonality of IMFs can be verified, and a significance test against white noise can 


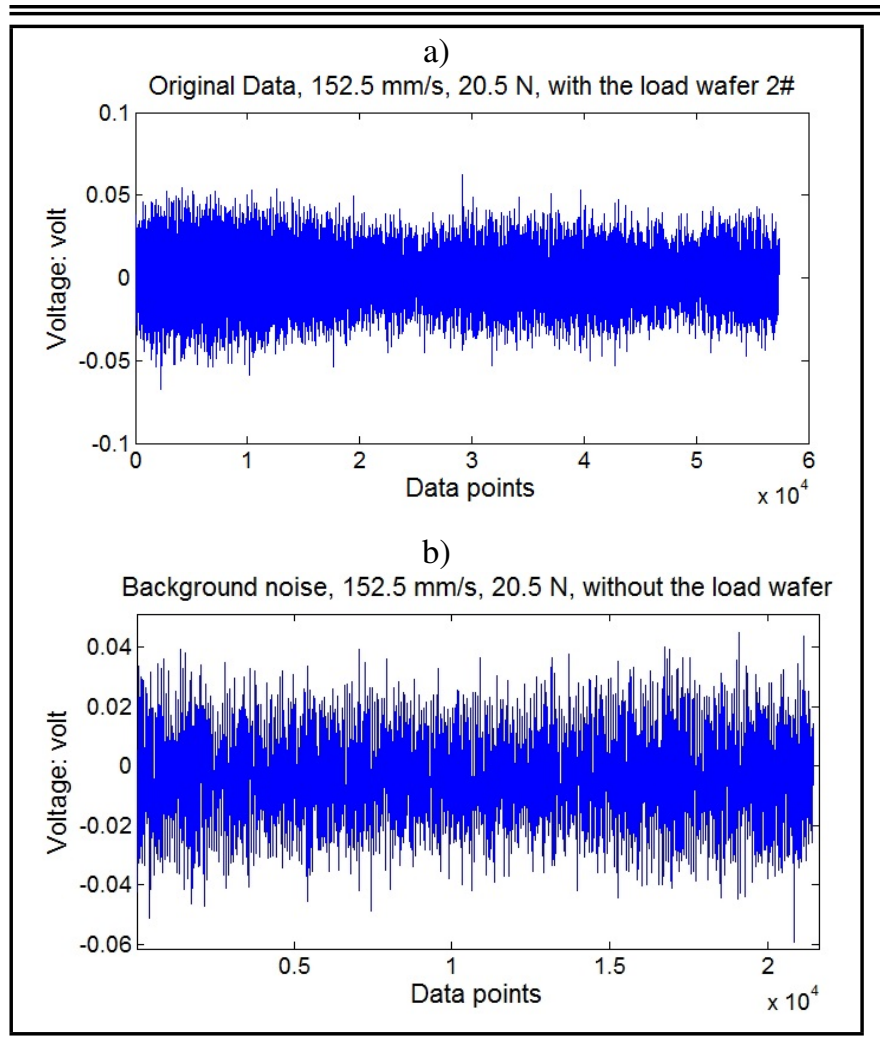

Figure 2. a) Original data with load wafer 2\# passing by the Mic; b) original data without loading

be performed. Finally, the HSP, designated as $\mathbf{H}(\omega, \mathbf{t})$, and defined as the energy density distribution in the time-frequency space, which was divided into equally sized bins of $\Delta t \times \Delta \omega$, each with the value $\alpha_{i, j}^{2} /(\Delta t \times \Delta \omega)$, is defined as follows:

$$
H\left(\omega_{j}, t_{i}\right)=\left(\sum_{j} \sum_{i} \alpha_{i, j}^{2}\right) /(\Delta t \times \Delta \omega) ;
$$

where $t_{i}=t_{0}+\mathbf{i} \times \Delta t, \omega_{j}=\omega_{0}+\mathbf{j} \times \Delta \omega$. From Eq. (3), MSP is defined as follows:

$$
\omega(\omega)=\int_{0}^{T} H(\omega, t) d t=\sum_{i=1}^{N} H\left(\omega, t_{i}\right) ;
$$

where $T$ is the total data span and $N$ is equal to $T / \Delta t$.

\subsubsection{EEMD}

Based on the original EMD method, Wu and Huang proposed EEMD by adding finite-amplitude white noise to the data and using a sifting process similar to that of EMD. ${ }^{31}$ The noise-impregnated data could be decomposed into IMFs and a residue. After a number of trials, in which the added noise series were different and the amplitudes were finite (expressed as the ratio $\sigma$ of the root mean square of the added noise and the standard deviation of the targeted data), the ensemble means of the corresponding IMFs of the decomposition were treated as the final results.

Wang and Yeh et al. proved that the time complexity of the EMD/EEMD is actually equivalent to that of the Fourier Transform. ${ }^{38}$ Numerical examples are presented to verify that
EMD/EEMD is, in fact, a computationally efficient method. Finally, a fast EEMD program is presented.

\subsection{Sound Analysis}

In this section, by using the above mentioned HHT method, the energized component extraction effects of system parameters on the vibration of the plate and marginal spectrum-based monitoring, are discussed. By comparing the MSP corresponding to the loading wafer to that of the background noise, distinctions between them could be observed in most cases. This allowed for the possibility of extracting useful features.

\subsubsection{Main component extraction}

In Fig. 2a, an original data series (length of 57,373 points), corresponding to load wafer \#2 passing by the Mic, is shown. Fig. $2 b$ shows the original background noise, or environmental noise (length of 21,436 points), picked up without the load wafer, when the transporting system was running. As shown in Fig. 1, two guides constrain the vibration of each string unilaterally. In this experiment, only one solar wafer was carried by the strings at a time. The thin plate is the load on the moving strings. The interactions between the strings, guide and plate, and driving motor, were the main sound sources. Through the EEMD in which $\sigma$, the ratio of the root-mean-square value of the added white noise to the standard deviation of the data series, was set to 0.2 , and the ensemble number nt (defined in the program 37, usually set between 100 and 500) was set to 400. In this study, the same values were used in all EEMD calculations. The detailed calculation procedures can be found in. ${ }^{32,33,35,36}$ Time-frequency features such as HSP, MSP, and energized IMFs and IFs were extracted.

By decomposing, orthogonal checking, and combining, and using the significance test of the IMFs, 36 HSPs could be obtained and are presented in Fig. 3. As shown in Fig. 3a, within $0-1 \mathrm{~s}$, there was an area of energy concentration, which corresponded to the period of the wafer passing over the Mic. However, the energy distribution of the background noise in Fig. $3 b$ is dispersive. Note that, here, the significance test was based on the assumption that the noise was white. To check this assumption, the Hurst exponents were estimated using the Matlab function wfbmestic and the highest frequency components, which were obtained by decomposing the original sound series, shown in Fig. 2a, by EMD. The Hurst exponents were $0.0146,0.4609$, and 0.4816 , respectively corresponding to the highest, sum of two highest, and sum of three highest components used to estimate the exponents. In this case, there were obvious differences between the estimated Hurst and 0.5. The background noise in Fig. $2 b$ should not have been white. The significance test was only used to filter out the highest component after EEMD.

Figure 4a shows the marginal spectra corresponding to the data series in Fig. 2a and 2b. Compared to the MSP of background noise, there is a resonance peak at approximately $40 \mathrm{~Hz}$ in the MSP with the load wafer. Considering that the central frequencies of the HSPs, of the two cases in Fig. 3, are 


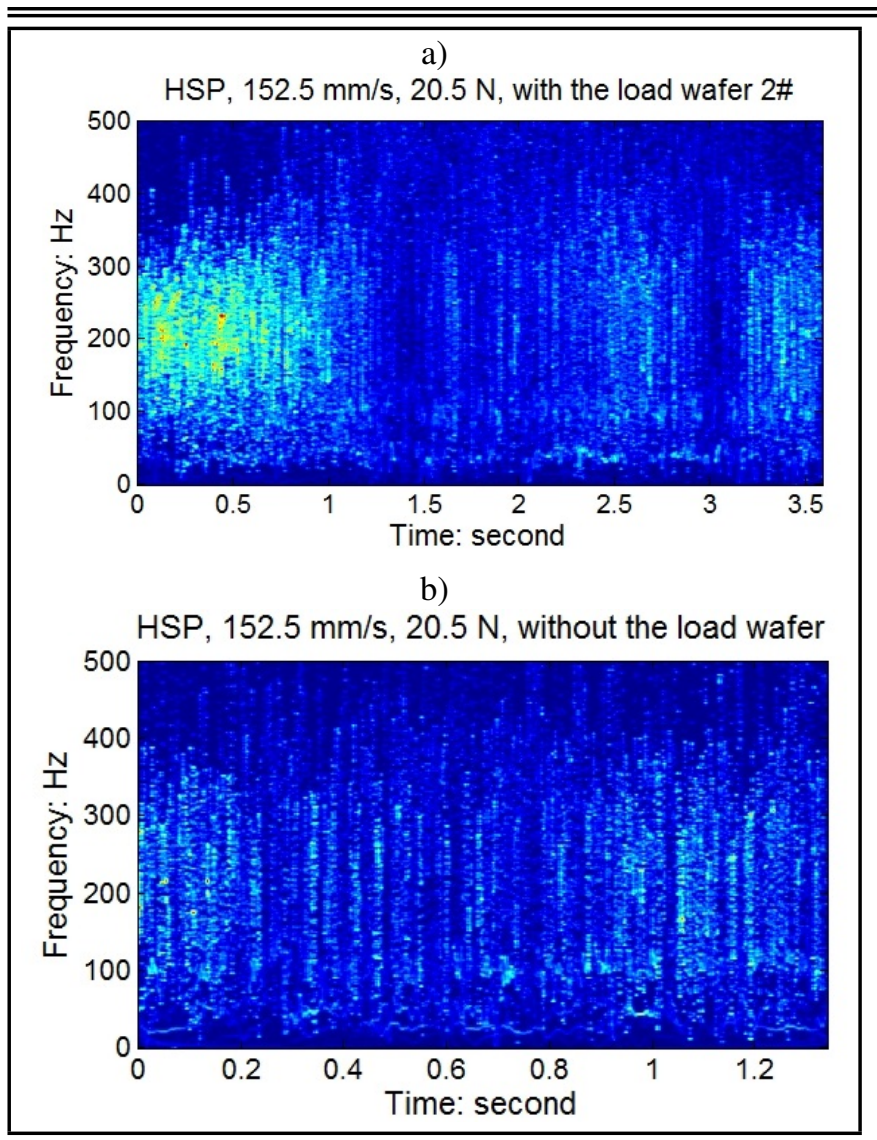

Figure 3. a) Hilbert-Huang spectrum, moving speed $152.5 \mathrm{~mm} / \mathrm{s}$, initial tension in the string $20.5 \mathrm{~N}$, with load wafer \#2; b) HSP of background noise, without load wafer.

the same (approximately $200 \mathrm{~Hz}$ ), there exists strong energy mixing when the wafer is passing. It is difficult to separate the characteristic component of the moving wafer at this frequency. Fig. $4 \mathrm{~b}$ shows the comparison of the two MSPs, when the initial tension is at $30 \mathrm{~N}$. Corresponding to the moving wafer, 3 peaks can be seen. The main components, under the two initial tensions and their instantaneous frequencies, are presented in Fig. 5. In Fig. 5b, the average IF is approximately $41.142 \mathrm{~Hz}$. In Fig. 5d, the average IFs are 102.6225, 46.1130, and $25.5520 \mathrm{~Hz}$, for IMF3, IMF4, and IMF5, respectively.

Figure 6 shows the comparison of MSPs in six cases. In Fig. 6 a, b, c, and d, the differences in marginal spectra between the background noise and sound with the load wafer are obvious; therefore, the main vibrating component(s) of the wafer can be extracted with higher credibility. In Fig. 6e, when the speed is $915 \mathrm{~mm} / \mathrm{s}$, the two curves have high similarity, and the signal corresponding to the moving wafer is swamped out by background noise. In Fig. 6f, the low frequency component, in the range of $20-50 \mathrm{~Hz}$, can be extracted.

\subsubsection{Effects of system parameters}

System parameters such as speed, string initial tension, and varying loading, exert effects on wafer vibration. In this section, the results related to a few cases involving five speeds and two initial tensions are presented. The data series lengths were $22,000,14,000,8,600,7,000$, and 6,500 points, corresponding to $152.5,305,457.5,610$, and $762.5 \mathrm{~mm} / \mathrm{s}$, respectively.

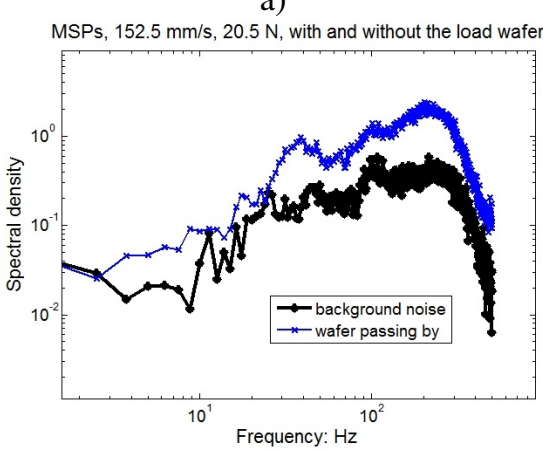

b)

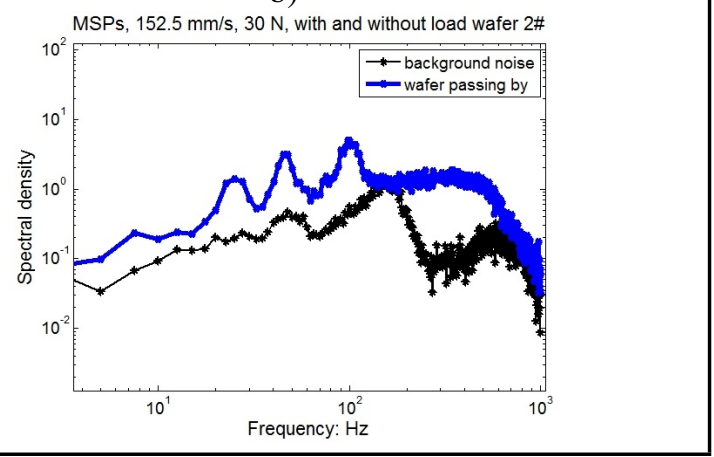

Figure 4. a) Marginal spectra, speed $152.5 \mathrm{~mm} / \mathrm{s}$, initial tension $20.5 \mathrm{~N}$, with and without load wafer; b) MSPs, $152.5 \mathrm{~mm} / \mathrm{s}, 30 \mathrm{~N}$, with and without load wafer.

EEMD $(\sigma=0.2, n t=400)$ was used and the averaged MSP was obtained by averaging 10 results for each case.

Figure 7 shows the average marginal spectra under five speeds, with an initial tension of $30 \mathrm{~N}$. The differences between the spectra are obvious. At speeds of 152.5 and $305 \mathrm{~mm} / \mathrm{s}$, besides a main energy peak, there were more than two subresonance peaks. From these curves, one can see that the motion is very sensitive to the moving speed.

Figure 8 presents the effects of initial tension in the MSP strings. In these cases, low tension induces high spectral density.

In Fig. 9a, when the speed is $762.5 \mathrm{~mm} / \mathrm{s}$, there are relatively small differences caused by the wafers. At $610 \mathrm{~mm} / \mathrm{s}$, the MSPs in Fig. 9b tend to converge. This shows that under certain conditions, the average MSP can be stable. As shown in Fig. 9c and 9d, MSP curves of wafer 1\# and 2\# under two speeds are plotted; their weight difference is very small, the vibration details are not the same, but the overall shapes are similar.

\subsubsection{Comparisons of the results using capacitance sensor S2 and Mic}

In Fig. 10, using a capacitance sensor S2 and the Mic, the MSPs of wafer 1\# under two speeds are shown. From the plots, the main energetic peaks coincide; the spectra at the relative high frequencies obtained by capacitance sensor fall rapidly. The reason for this should be the averaging effect of the capacitance sensor. 


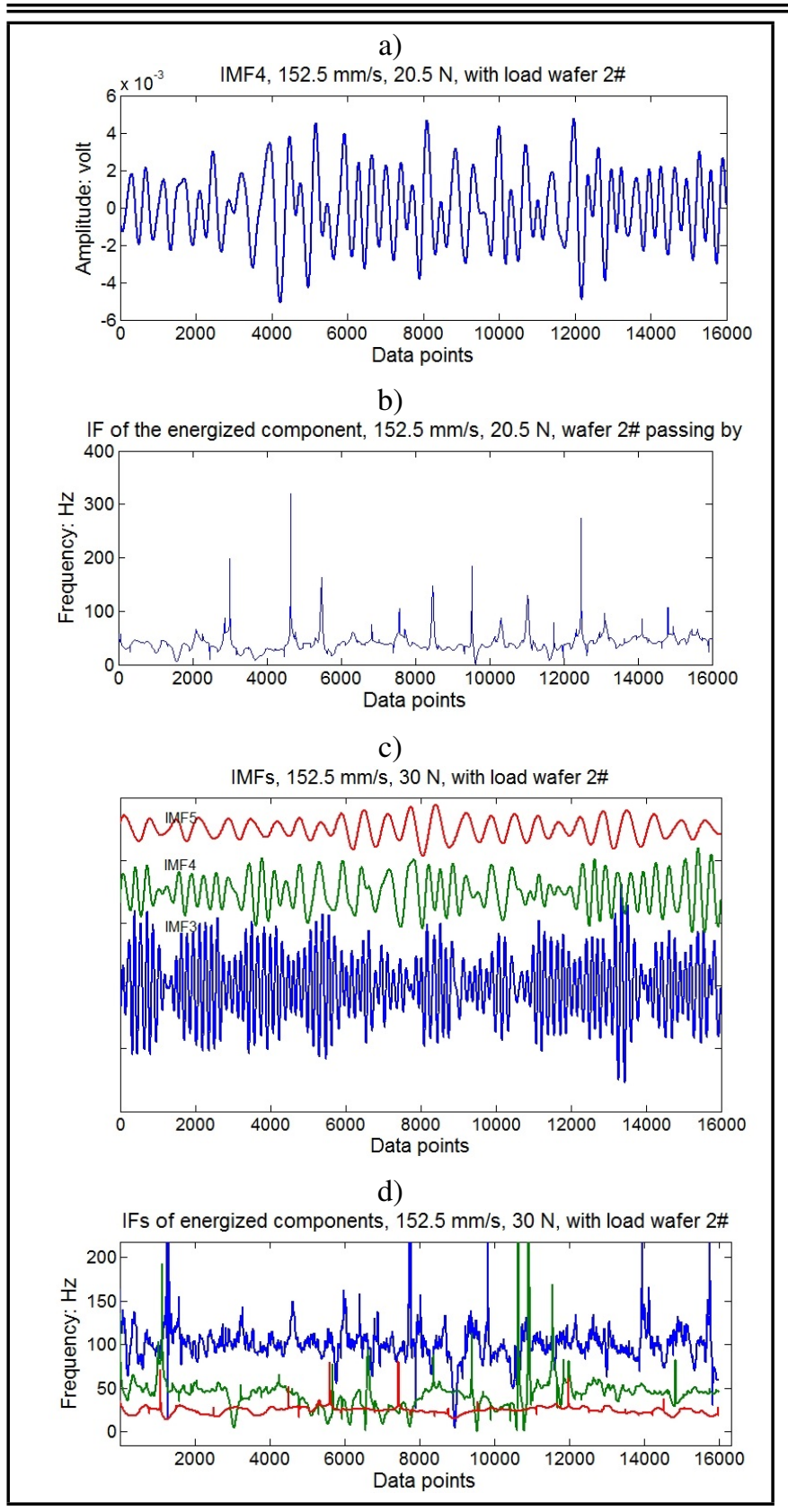

Figure 5. a) Main component of moving wafer, extracted from signal in Fig. 2a; b) Instantaneous frequency of Fig. 5a; c) Main components, speed $152.5 \mathrm{~mm} / \mathrm{s}$, initial tension $30 \mathrm{~N}$; d) IFs of the three components.

\subsubsection{Monitoring method}

From the above analysis, it follows that the vibrating motion of the plate/wafer is sensitive to system parameters. In a certain system configuration, the average marginal spectrum demonstrates a certain stability. In particular, for a certain measuring system with a strict requirement of motion smoothness, the average marginal spectrum, or a certain threshold based on the maximum energy density, can be used to monitor the abnormal variations in string tension, speed, and motion of the plate during long-term running.

\section{CONCLUSIONS}

Based on a sound data series and by using HHT, which is a time-frequency analysis method, the low frequency features of the moving wafer could be determined quantitatively. The motion of the moving wafer sensitive to speed and string tension is verified.

In comparison to the expensive capacitive sensor, ${ }^{34}$ a lowcost microphone could be used to pick up the sound caused by the interactions in the system. Through data analysis, the average marginal spectrum should be treated as a basis of comparison for qualitative vibration monitoring, particularly for a certain measuring system with a strict requirement of motion smoothness.

\section{REFERENCES}

${ }^{1}$ Marynowski, K. and Kapitaniak, T. Dynamics of axially moving continua, International Journal of Mechanical Sciences, 81 (4), 26-41, (2014). https://dx.doi.org/10.1016/j.ijmecsci.2014.01.017

2 Wang, X. D. Numerical analysis of moving orthotropic thin plates, Computers and Structures, 70 (4), 467-486,(1996). https://dx.doi.org/10.1016/S0045-7949(98)00161-8

${ }^{3}$ Kim, J., Cho, J., Lee, U., and Park, S. Modal spectral element formulation for axially moving plates subjected to in-plane axial tension, Computers and Structures, 81 (20), 2011-2020,(2003). https://dx.doi.org/10.1016/S00457949(03)00229-3

${ }^{4}$ Hatami, S., Azhari, M., and Saadatpour, M. M. Free vibration of moving laminated composite plates, Composite Structures, 80 (4), 609-620, (2007). https://dx.doi.org/10.1016/j.compstruct.2006.07.009

${ }^{5}$ Hatami, S., Ronagh, H. R., and Azhari, M. Exact free vibration analysis of axially moving viscoelastic plates, Computers and Structures, 86 (17-18), 1738-1746, (2008). https://dx.doi.org/10.1016/j.compstruc.2008.02.002

${ }^{6}$ Zhou, Y. F. and Wang, Z. M. Transverse vibration characteristics of axially moving viscoelastic plate, Applied Mathematics and Mechanics (English Edition), 28 (2), 209-218, (2007). https://dx.doi.org/10.1007/s10483-007-0209-1

7 Zhou, Y. F. and Wang, Z. M. Vibration of axially moving viscoelastic plate with parabolically varying thickness, Journal of Sound and Vibration, 316 (1-5), 198-210, (2008). https://dx.doi.org/10.1016/j.jsv.2008.02.040

8 Yang, X. D., Zhang, W., Chen, L. Q., and Yao, M. H. Dynamical analysis of axially moving plate by finite difference method, Nonlinear Dynamics, 67 (2), 997-1006, (2012). https://dx.doi.org/10.1007/s11071-011-0042-2

9 Ghayesh, M. H. and Amabili, M. Non-linear global dynamics of an axially moving plate, International Journal of Non-linear Mechanics, 57 (4), 16-30, (2013). https://dx.doi.org/10.1016/j.ijnonlinmec.2013.06.005 


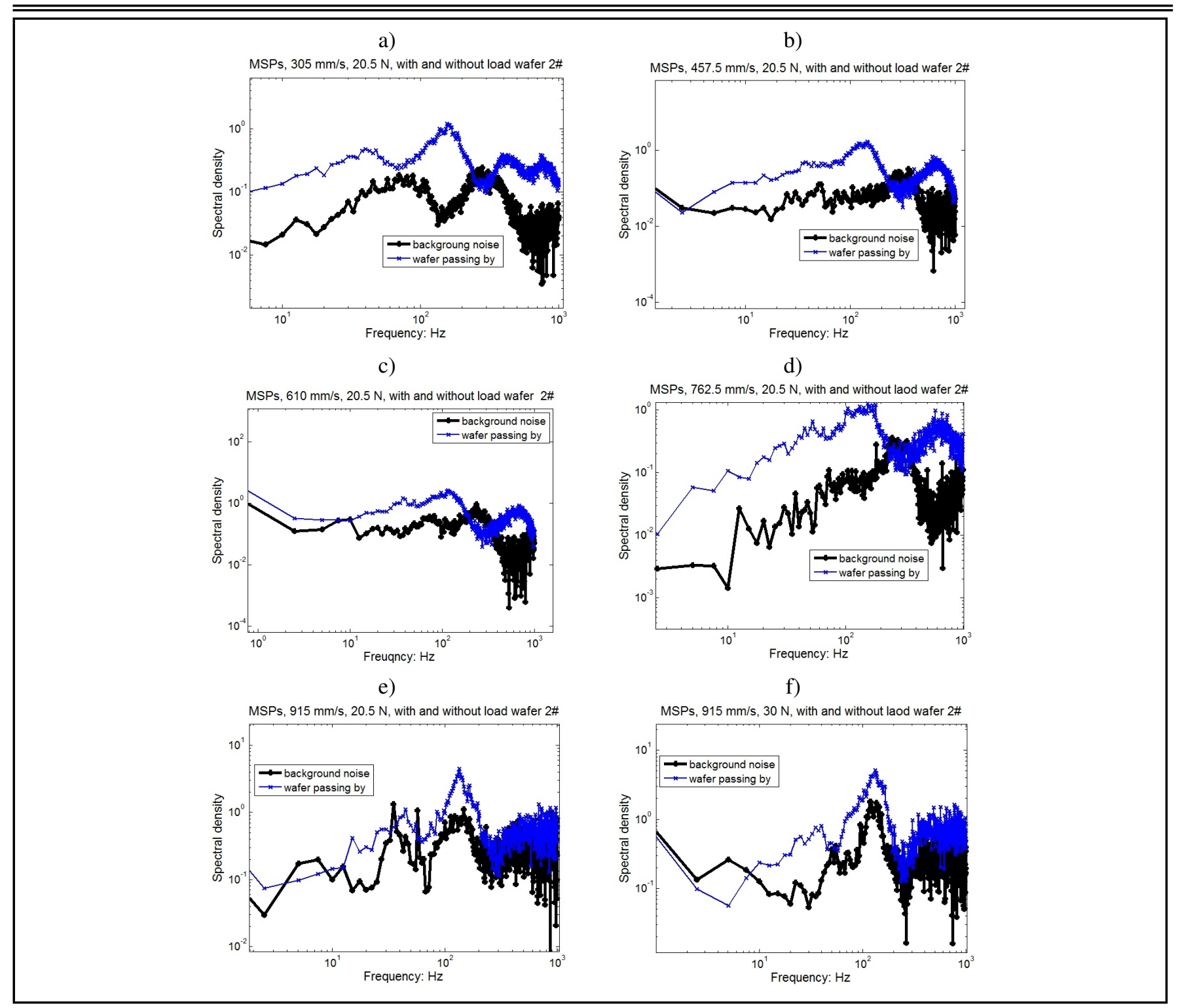

Figure 6. Comparison of MSPs. a) $305 \mathrm{~mm} / \mathrm{s}, 20.5 \mathrm{~N}$; b) $457.5 \mathrm{~mm} / \mathrm{s} ; 20.5 \mathrm{~N}$; c) $610 \mathrm{~mm} / \mathrm{s} ; 20.5 \mathrm{~N}$; d) $762.5 \mathrm{~mm} / \mathrm{s} ; 20.5 \mathrm{~N}$; e) $915 \mathrm{~mm} / \mathrm{s}, 20.5 \mathrm{~N}$; f) $915 \mathrm{~mm} / \mathrm{s}$, $30 \mathrm{~N}$.

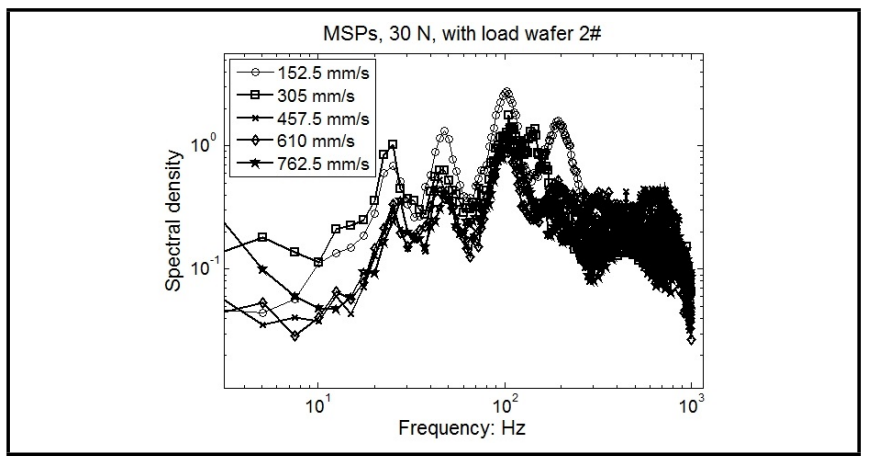

Figure 7. Comparison of MSPs, five speeds, same tension of $30 \mathrm{~N}$.

10 Ghayesh, M. H., Amabili, M., and Païdoussis, M. P. Nonlinear dynamics of axially moving plates, Journal of Sound and Vibration, 332 (2), 391-406, (2013). https://dx.doi.org/10.1016/j.jsv.2012.08.013

11 Ghayesh, M. H. and Païdoussis, M. P. Threedimensional dynamics of a cantilevered pipe conveying fluid, additionally supported by an in- termediate spring array, International Journal of Non-Linear Mechanics, 45 (5), 507-524, (2010). https://dx.doi.org/10.1016/j.ijnonlinmec.2010.02.001

12 Sahebkar, S. M., Ghazavi, M. R., Khadem, S. E., and Ghayesh, M. H. Nonlinear vibration analysis of an axially moving drillstring system with time dependent axial load and axial velocity in inclined well, Mechanism and Machine Theory, 46 (5), 743-760, 2011. https://dx.doi.org/10.1016/j.mechmachtheory.2010.12.003

13 Ghayesh, M. H., Païdoussis, M. P., and Amabili, M. Nonlinear dynamics of cantilevered extensible pipes conveying fluid, Journal of Sound and Vibration, 332 (24), 64056418, (2013). https://dx.doi.org/10.1016/j.jsv.2013.06.026

14 Ghayesh, M. H., Amabili, M., and Païdoussis, M. P. Nonlinear vibrations and stability of an axially moving beam with an intermediate spring support: two-dimensional analysis, Nonlinear Dynamics, 70 (70), 335-354, (2013). https://dx.doi.org/10.1007/s11071-012-0458-3 


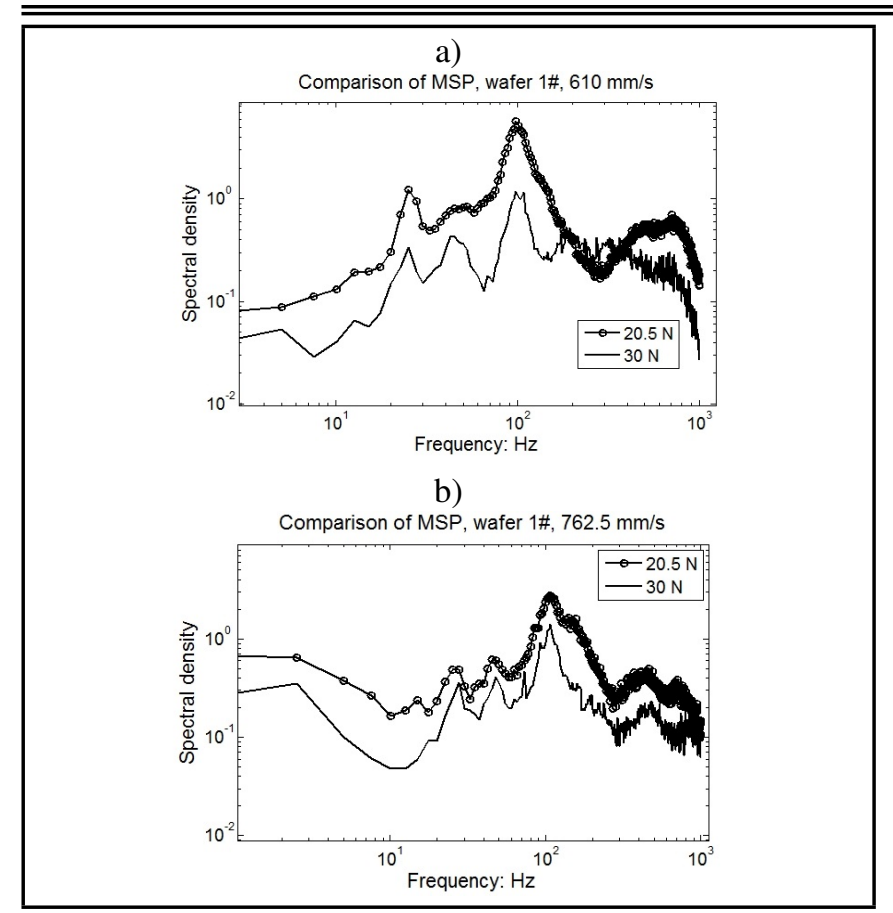

Figure 8. Comparison of MSP. a) Average marginal spectra, $610 \mathrm{~mm} / \mathrm{s}$; b) Average marginal spectra, $762.5 \mathrm{~mm} / \mathrm{s}$.

15 Ghayesh, M. H., Kazemirad, S., and Amabili, M. Coupled longitudinal-transverse dynamics of an axially moving beam with an internal resonance, Mechanism and Machine Theory, 52 (3), 18-34, (2012). https://dx.doi.org/10.1016/j.mechmachtheory.2012.01.008

16 Ghayesh, M. H. Stability and bifurcations of an axially moving beam with an intermediate spring support, Nonlinear Dynamics, 69 (1-2), 193-210, (2012). https://dx.doi.org/10.1007/s11071-011-0257-2

17 Ghayesh, M. H. and Amabili, M. Nonlinear vibrations and stability of an axially moving Timoshenko beam with an intermediate spring support, Mechanism and Machine Theory, 67 (67), 1-16, (2013). https://dx.doi.org/10.1016/j.mechmachtheory.2013.03.007

18 Ghayesh, M. H. Subharmonic dynamics of an axially accelerating beam, Archive of Applied Mechanics, 82 (9), 11691181, (2012). https://dx.doi.org/10.1007/s00419-012-06095

19 Ghayesh, M. H., Yourdkhani, M., Balar, S., and Reid, T. Vibrations and stability of axially traveling laminated beams, Applied Mathematics \& Computation, 217 (2), 545-556, (2010). https://dx.doi.org/10.1016/j.amc.2010.05.088

20 Saksa, T., Banichuk, N., Jeronen, J., Kurki, M., and Tuovinen, T. Dynamic analysis for axially moving viscoelastic panels, International Journal of Solids and Structures, 49 (23-24), 3355-3366, (2012). https://dx.doi.org/10.1016/j.ijsolstr.2012.07.017

21 Tang, Y. Q. and Chen, L. Q. Stability analysis and numerical confirmation in parametric resonance of axially moving viscoelastic plates with time-dependent speed, European a)

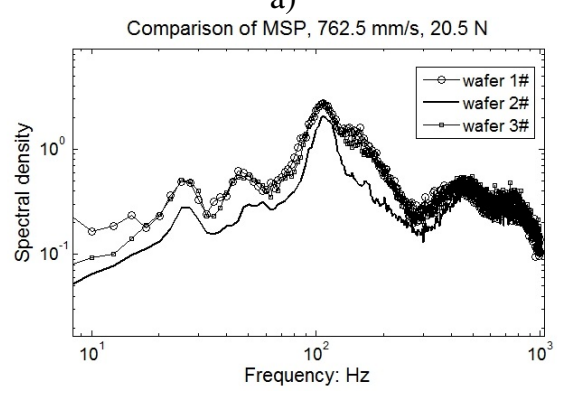

b)

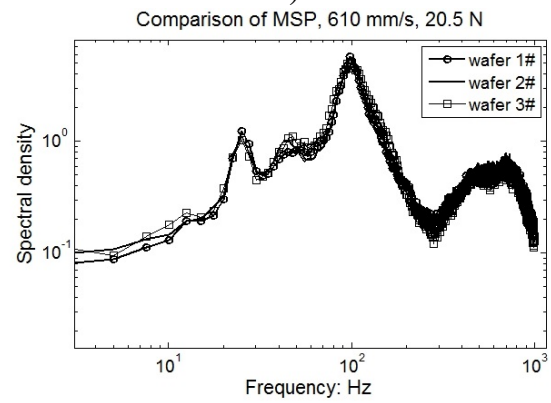

c)

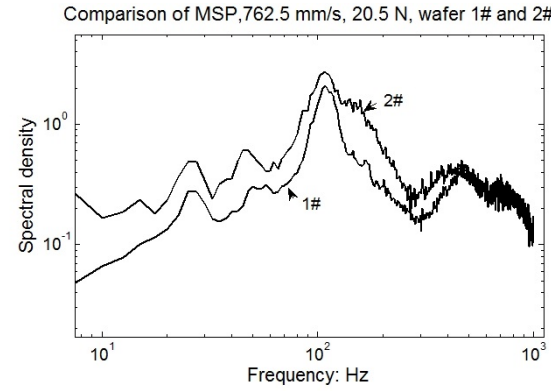

d)

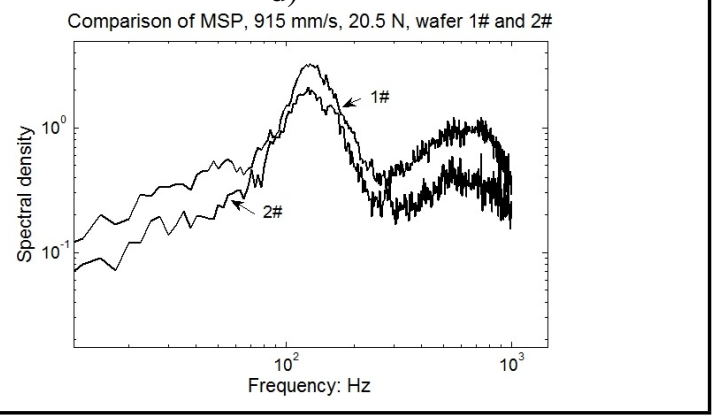

Figure 9. Comparison of MSP. a) Average marginal spectra, different wafers, $762.5 \mathrm{~mm} / \mathrm{s}$; b) Average marginal spectra, different wafers, $610 \mathrm{~mm} / \mathrm{s} ; \mathrm{c}$ ) MSPs of wafer 1\# and 2\#, $762.5 \mathrm{~mm} / \mathrm{s}$; d) MSPs of wafer 1\# and 2\#, $915 \mathrm{~mm} / \mathrm{s}$.

Journal of Mechanics A/solids, 37 (37), 106-121, 2013. https://dx.doi.org/10.1016/j.euromechsol.2012.05.010

22 Marynowski, K. and Kapitaniak, T. Kelvin-Voigt versus Burgers internal damping in modeling of axially moving viscoelastic web, International Journal of Non-linear Mechanics, 37 (7), 1147-1161, (2002). https://dx.doi.org/10.1016/S0020-7462(01)00142-1

23 Ghayesh, M. H. Nonlinear transversal vibration and stability of an axially moving viscoelastic string supported by a partial viscoelastic guide, Journal of Sound and Vibration, 314 (3-5), 757-774, (2008). https://dx.doi.org/10.1016/j.jsv.2008.01.030 


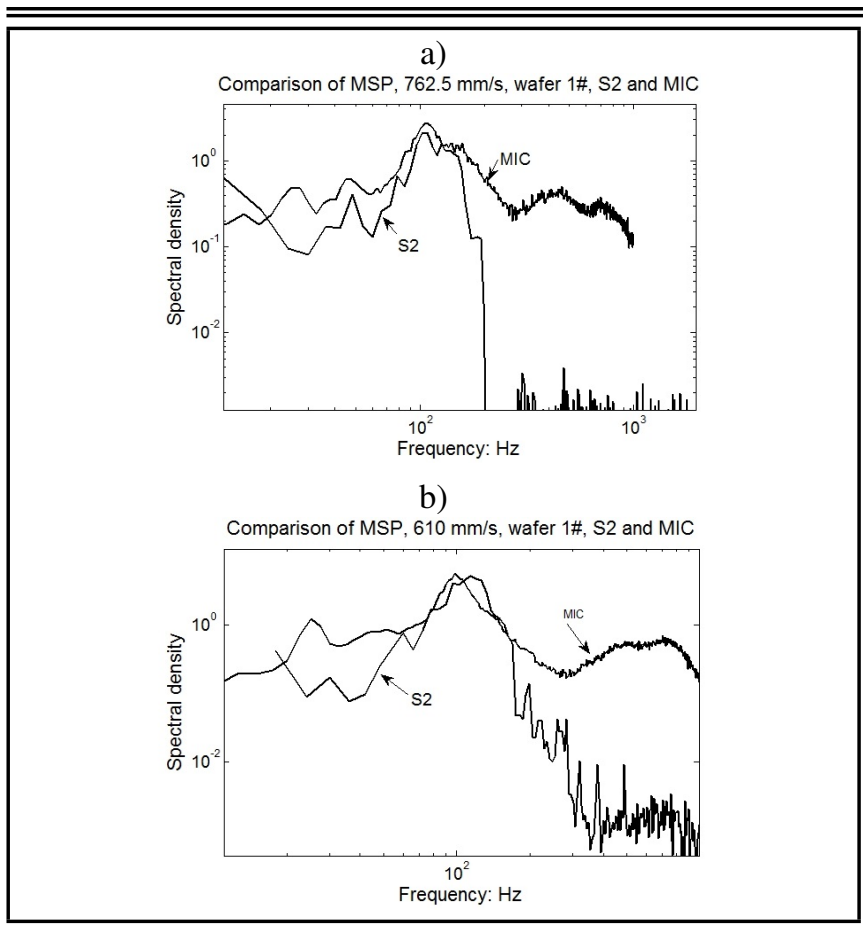

Figure 10. Comparison of MSP using S2 and MIC. a) MSP using capacitance sensor S2 and Mic, $762.5 \mathrm{~mm} / \mathrm{s}, 20.5 \mathrm{~N}$; b) MSP, $610 \mathrm{~mm} / \mathrm{s}, 20.5 \mathrm{~N}$.

${ }^{24}$ Ghayesh, M. H. and Amabili, M. Nonlinear dynamics of axially moving viscoelastic beams over the buckled state, Computers \& Structures, s112-113 (12), 406-421, (2012). https://dx.doi.org/10.1016/j.compstruc.2012.09.005

${ }^{25} \mathrm{Li}$, H. Y., Li, J., and Liu, Y. J. Internal resonance of an axially moving unidirectional plate partially immersed in fluid under foundation displacement excitation, Journal of Sound and Vibration, 358, 124-141, (2015). https://dx.doi.org/10.1016/j.jsv.2015.07.030

26 Tang, Y. Q., Zhang, D. B., and Gao, J. M. Vibration characteristic analysis and numerical confirmation of an axially moving plate with viscous damping, Journal of Vibration and Control, (2015). https://dx.doi.org/10.1177/1077546315586311

27 Wang, Y. Q., Du, W., Huang, X.B., and Xue, S. W. Study on the dynamic behavior of axially moving rectangular plates partially submersed in fluid, Acta Mechanica Solida Sinica, 28 (6), 706-721, (2015). https://dx.doi.org/10.1016/S08949166(16)30011-8

${ }^{28}$ Kesimli, A., Özkaya, E., and Bağdatli, S. M. Nonlinear vibrations of spring-supported axially moving string, Nonlinear Dynamics, 81 (3), 1523-1534, (2015). https://dx.doi.org/10.1007/s11071-015-2086-1

29 Moon, J. and Wickert, J. A. Nonlinear vibration of power transmission belts, Journal of Sound and Vibration, 200 (4), 419-431, (1997). https://dx.doi.org/10.1006/jsvi.1996.0709
${ }^{30}$ Pellicano, F., Fregolent, A., Bertuzzi, A., and Vestroni, F. Primary and parametric nonlinear resonances of a power transmission belt: experimental and theoretical analysis, Journal of Sound and Vibration, 244 (4), 669-684, (2001). https://dx.doi.org/10.1006/jsvi.2000.3488

${ }^{31}$ Pellicano, F., Catellani, G., and Fregolent, A. Parametric instability of belts: theory and experiments, Computers and Structures, 82 (1), 81-91, (2004). https://dx.doi.org/10.1016/j.compstruc.2003.07.004

${ }^{32}$ Xia, C. L., Wu, Y. F., and Lu, Q. Q. Transversal vibration analysis of an axially moving string with unilateral constraints using the HHT method, Mechanical Systems and Signal Processing, 39 (1-2), 471-488, (2013). https://dx.doi.org/10.1016/j.ymssp.2013.01.018

${ }^{33}$ Xia, C. L., Wu, Y. F., and Lu, Q. Q. Experimental study of the nonlinear characteristics of an axially moving string, Journal of Vibration and Control, 21 (16), 3239-3253, (2014). https://dx.doi.org/10.1177/1077546314520832

${ }^{34} \mathrm{Wu}$, Y. F., Lu, Q. Q., and Xia, C. L. An analysis of the vibrating motion of an axially moving thin plate using the HHT method, Journal of Vibroengineering, 17 (8), 41224133, (2015).

35 Huang, N. E., Shen, Z., Long, S. R., Wu, M. C., Shih, H. H., Zhang, Q. Yen, N. C., Tung, C. C., and Liu, H. H. The empirical mode decomposition method and the Hilbert spectrum for non-stationary time series analysis, In Proceedings of the Royal Society of London, 454A, 903-995, (1998). https://dx.doi.org/10.1098/rspa.1998.0193

$36 \mathrm{Wu}, \mathrm{Z}$. H. and Huang, N. E. Ensemble empirical mode decomposition: a noise-assisted data analysis method, $A d$ vances in Adaptive Data Analysis, 1 (1), 1-41, (2009). https://dx.doi.org/10.1142/S1793536909000047

37 EEMD/EMD program and the utilities for HHT calculations. Retrieved from http://rcada.ncu.edu.tw, (Accessed on August 06, 2012).

38 Wang, Y. H., Yeh, C. H. Young, H.W.V., Hu, K., and Lo, M. T. On the computational complexity of the empirical mode decomposition algorithm, Physica a Statistical Mechanics \& Its Applications, 400 (2), 159-167, (2014). https://dx.doi.org/10.1016/j.physa.2014.01.020

${ }^{39}$ Feng, Z. P., Liang, M., and Chu, F. L. Recent advances in time-frequency analysis methods for machinery fault diagnosis: a review with application examples, Mechanical Systems and Signal Processing, 38 (1), 165-205, (2013). https://dx.doi.org/10.1016/j.ymssp.2013.01.017 